\title{
Tumour necrosis factor gene polymorphism: a predictive factor for the development of post-transplant lymphoproliferative disease
}

\author{
KA McAulay*,', T Haque ${ }^{2}$ and DH Crawford' \\ 'Clinical and Basic Virology Laboratory, School of Biomedical Sciences, University of Edinburgh, Summerhall, Edinburgh EH9 IQH, UK; ${ }^{2}$ Centre for \\ Virology, UCL Medical School, Royal Free Campus, Rowland Hill Street, London NW3 2PF, UK
}

\begin{abstract}
BACKGROUND: Epstein-Barr virus-positive post-transplant lymphoproliferative disease (PTLD) is a potentially lethal complication of iatrogenic immunosupression after transplantation. Predicting the development of PTLD allowing early and effective intervention is therefore of importance. Polymorphisms within cytokine genes are implicated in susceptibility to, and progression of, disease however the published data are often conflicting. We undertook investigation of polymorphic alleles within cytokine genes in PTLD and nonPTLD transplant cohorts to determine risk factors for disease.

METHODS: SSP-PCR was used to analyse single nucleotide polymorphism within tumour necrosis factor (TNF)- $\alpha$, interleukin- I, -6, - I0 and lymphotoxin- $\alpha$ genes. The TNF- $\alpha$ levels were measured by standard enzyme-linked immuno-absorbant assay.

RESULTS: We show an association between variant alleles within the TNF- $\alpha$ promoter $(-103 \mathrm{IC}(P=0.005)) ;-863 \mathrm{~A}(P=0.000 \mathrm{I})$ and TNF receptor I promoter regions $(-201 \mathrm{~T}(P=0.02)) ;-1135 \mathrm{C}(P=0.03)$ with the development of PTLD. We also show an association with TNF- $\alpha$ promoter haplotypes with haplotype-3 significantly increased $(P=0.000 \mathrm{I})$ and haplotype-I decreased $(P=0.02)$ in PTLD patients compared to transplant controls. Furthermore, we show a significant increase $(P=0.02)$ in the level of TNF- $\alpha$ in PTLD patient plasma (range $0-97.97 \mathrm{pg} \mathrm{m}^{-1}$ ) compared to transplant controls $\left(0-8.147 \mathrm{pg} \mathrm{ml}^{-1}\right.$ ), with the highest levels found in individuals carrying the variant alleles.

CONCLUSION: We suggest that genetic variation within TNF- $\alpha$ loci and the level of plasma cytokine could be used as a predictive risk factor for the development of PTLD.

British Journal of Cancer (2009) I 01, 1019 - 1027. doi: I0.1038/sj.bjc.6605278 www.bjcancer.com
\end{abstract}

(c) 2009 Cancer Research UK

Keywords: PTLD; EBV; cytokine; polymorphism; TNF

Post-transplant lymphoproliferative disease (PTLD) is a potentially lethal complication of iatrogenic immunosupression after solid organ transplant (SOT) and bone marrow transplantation (Paya et al, 1999; Nalesnik, 2002). It occurs in up to $10 \%$ of all transplant recipients and in most cases is associated with Epstein-Barr virus (EBV) infection, a gammaherpes virus that infects around $90 \%$ of the adult population. On primary EBV infection the virus establishes a life-long asymptomatic infection in circulating B lymphocytes that are effectively controlled by EBV-specific cytotoxic T lymphocytes (CTLs). In transplant recipients, however, the immunosuppressive drug regimens used to control organ rejection, suppress the function of EBV-specific CTLs and can lead to the uncontrolled proliferation of EBV infected B lymphocytes and tumour formation. Reduction of immunosupression, radiotherapy, chemotherapy, surgery and monoclonal antibody-based regimens (Swinnen et al, 1995; Choquet et al, 2006) are routinely used to treat the disease on presentation of tumour, but even with

\footnotetext{
*Correspondence: Dr KA McAulay, Clinical and Basic Virology Laboratory, School of Biomedical Sciences, University of Edinburgh, I Summerhall Square, Edinburgh EH9 IQH, UK;

E-mail: kmcaulay@ed.ac.uk

Received 2 April 2009; revised 23 June 2009; accepted 27 July 2009
}

such treatment options the mortality rate is approximately $50 \%$ (Opelz and Dohler, 2004; Choquet et al, 2007). More recently, infusions of ex-vivo expanded EBV-specific CTLs to selectively reconstitute $\mathrm{EBV}$-specific immunity have proven useful in the treatment and prevention of EBV-positive PTLD (Savoldo et al, 2006; Haque et al, 2007). Strategies to predict the impending development of PTLD allowing early and effective intervention are therefore assuming increasing importance. A raised EBV viral load post transplant is one suggested marker of PTLD development (Riddler et al, 1994; Davis et al, 2004); however, the published data are contradictory with recent studies reporting that a high EBV viral load does not predict PTLD development post transplant (Benden et al, 2005; Sato et al, 2008; Wheless et al, 2008). More robust strategies are therefore required especially with the advent of promising new immunotherapies such as CTL infusion into the clinical setting.

Cytokine networks interact in a dynamic way to regulate the immune response, thus it is not surprising that variations in cytokine levels have been correlated with susceptibility to disease and disease progression (Brennan and McInnes, 2008; Feldmann, 2008). A fundamental issue of such studies is whether variation in the level of a secreted cytokine is the primary cause for the disease or a secondary downstream effect of the immune regulation process. Investigation of cytokine gene polymorphisms is one 
approach of unravelling this issue and may provide a genetic strategy for assigning a risk value to disease development.

Several studies have implicated polymorphisms within cytokine genes with the risk of symptomatic primary EBV infection (Hurme and Helminen, 1998; Helminen et al, 1999) and with the development of EBV-associated tumours. Interleukin (IL)-18 variants, for example, have been associated with more aggressive forms of nasopharyngeal carcinoma, whereas in contrast to a protective role in EBV-associated infectious mononucleosis (Helminen et al, 1999), the high producer IL-10 haplotype has been associated with EBV-positive gastric cancer (Wu et al, 2002; Pratesi et al, 2006). The low producer interferon gamma (IFN- $\gamma$ ) genotype has been implicated in EBV reactivation after stem cell transplantation and with the development of PTLD after renal and liver transplantation (VanBuskirk et al, 2001; Bogunia-Kubik et al, 2006; Lee et al, 2006). However, we recently investigated the low producer IFN- $\gamma$ genotype in EBV-positive PTLD after various SOTs and found no association with the development of disease (Thomas et al, 2005). A more recent study investigating late-onset PTLD showed an association with tumour growth factor- $\beta 1$ and IL-10 but not IFN- $\gamma$ genotypes (Babel et al, 2007). The reasons for these observed differences are unknown but may, in part, be because of the difference in type of organ transplant, type of PTLD and/or small study cohorts.

Earlier studies have been criticised for use of small cohorts, unmatched controls and investigation of single polymorphic alleles (Ollier, 2004). Therefore, to resolve differences observed in the literature with regard to cytokine gene polymorphisms in EBVpositive PTLD, we analysed several cytokine gene and cytokine receptor gene polymorphisms (alleles, genotypes and haplotypes) in a large cohort of EBV-positive PTLD patients and appropriate controls to determine correlations, if any, with the development of disease.

\section{MATERIALS AND METHODS}

\section{Study cohort}

A cohort of EBV-associated PTLD patients was accrued as part of a phase II multi-centre clinical trial detailed in Haque et al (2007). Patients were recruited to the trial with informed written consent from patients or guardians. The study was approved by the Lothian Research Ethics Committee. Diagnosis of PTLD and its classification were determined by histological examination and EBV status determined by in situ hybridisation and immunohistocehemisrty methods (detailed in Haque et al (2007)). A blood sample was taken on diagnosis and plasma and peripheral blood mononuclear cells (PBMC) were collected.

An anonymised control cohort of EBV sero-positive heart transplant patients without any PTLD development was established from an earlier study investigating EBV infection in heart transplant patients (Hopwood et al, 2002). PBMC and plasma samples were prepared in a similar manner to PTLD patients.

Healthy EBV sero-positive individuals were recruited as part of an epidemiological study carried out at Edinburgh University. Details for enrolment and serotyping have been published elsewhere (Crawford et al, 2002, 2006). On recruitment, subjects provided a blood sample for EBV serology. PBMC and plasma samples were prepared as above.

\section{Cytokine polymorphism PCR}

DNA was extracted using the Easy-DNA kit (Invitrogen, Paisley, UK) and amplified in 47 separate PCR reactions using primers amplifying polymorphic regions within tumour necrosis factor(TNF)- $\alpha$, lymphotoxin (LT- $\alpha$ ), IL-1- $\alpha$, IL-6, IL-10, TNF receptor(R)I, TNFRII, IL-1R and IL-10R genes (Supplementary
Table 1). Each primer mix also contained a set of control primers. Between 60 and $80 \mathrm{ng}$ DNA were amplified in a reaction mix containing BioTaq DNA polymerase and reagents (Bioline, London, UK): $1 \times \mathrm{NH}_{4}$ buffer; $1.5 \mathrm{mM} \mathrm{MgCl}_{2} ; 200 \mu \mathrm{M}$ dNTPs and $0.35 \mathrm{U}$ Taq polymerase. Cycling parameters were staged as follows: $96^{\circ} \mathrm{C}$ for $1 \mathrm{~min} ; 4$ cycles of $96^{\circ} \mathrm{C}$ for $20 \mathrm{~s}, 75^{\circ} \mathrm{C}$ for $45 \mathrm{~s}, 72^{\circ} \mathrm{C}$ for $25 \mathrm{~s}$; 20 cycles of $96^{\circ} \mathrm{C}$ for $25 \mathrm{~s}, 65^{\circ} \mathrm{C}$ for $50 \mathrm{~s}, 72^{\circ} \mathrm{C}$ for $30 \mathrm{~s} ; 3$ cycles of $96^{\circ} \mathrm{C}$ for $30 \mathrm{~s}, 55^{\circ} \mathrm{C}$ for $60 \mathrm{~s}, 72^{\circ} \mathrm{C}$ for $90 \mathrm{~s} ; 5^{\circ} \mathrm{C}$ for $10 \mathrm{~min}$. The resultant PCR product was visualised on a $2 \%$ agarose-ethidium bromide gel under UV illumination.

\section{Enzyme-linked immuno-absorbant assay (ELISA)}

The level of human TNF- $\alpha$ was measured in plasma samples from PTLD patients, non-PTLD transplant control patients and healthy EBV sero-positive controls by quantitative ELISA (Mabtech, Nacka Strand, Sweden) following the manufacturer's instructions. Briefly, wells were coated overnight with the monoclonal antibody TNF- $\alpha$-I, washed and blocked before the addition of quantified TNF standards and patient plasma (undiluted). Plasma was allowed to absorb for $2 \mathrm{~h}$ and was then washed. Bound TNF- $\alpha$ was detected using the biotinylated monoclonal antibody to TNF- $\alpha$-II and streptavidin-alkaline phosphatase. The optical density at $405 \mathrm{~nm}$ was measured after $30 \mathrm{~min}$ incubation with the development substrate $p$-nitrophenyl-phosphate (Sigma, Gillingham, UK).

\section{Statistical methods}

Each polymorphism was tested for Hardy-Weinberg disequilibrium by comparing the observed allele frequency with the expected frequency if equilibrium applied. Classical association analysis was conducted to compare allele frequencies between the groups of subjects (PTLD-positive and PTLD-negative post transplant cohorts; PTLD positive and healthy control cohorts) and tested using the Fisher's exact or $\chi^{2}$ test (this was not adjusted for multiple testing). The Mann - Whitney $U$ test and the one-way ANOVA test were used to test for differences in the medians of quantitative variables. Tests were two-tailed and a $P$-value $<0.05$ was considered significant. All statistical analysis was performed using GraphPad PRISM software (GraphPad Software Inc., La Jolla, CA, USA).

\section{RESULTS}

Known polymorphic alleles/regions from the TNF- $\alpha$, LT- $\alpha$, IL-1- $\alpha$, IL-6, IL-10, TNFRI, TNFRII, IL-1R and IL-10R (detailed in Supplementary Table 1) were analysed in transplant patients with $(n=45)$ or without $(n=65)$ EBV-positive PTLD (designated PTLD and transplant control subject groups, respectively). Similar analyses were also performed on a healthy adult EBV sero-positive control cohort $(n=183)$. Both the transplant and healthy control cohorts were compared with published frequencies (HapMap Caucasian European (CEU) and CEU Geno frequencies; Pubmed SNP database www.Ncbi.nlm.nih.gov) to assess any variation from the normal expected frequencies: no major variation from expected frequencies was noted. All polymorphic alleles were found to be in Hardy-Weinberg equilibrium except for the single nucleotide polymorphism at position 230 (A/G base change) in the TNFRI promoter region within the transplant control group and therefore individual analysis of this allele was not performed.

\section{Increased frequency of the TNF promoter $-1031 \mathrm{C}$ and $-863 \mathrm{~A}$ variant alleles in PTLD subjects}

A total of five polymorphic alleles within the TNF promoter region (nucleotide positions relative to transcription start site $-1031(\mathrm{~T} / \mathrm{C})$, $-863(\mathrm{C} / \mathrm{A}), \quad-857(\mathrm{C} / \mathrm{T}), \quad-307(\mathrm{G} / \mathrm{A})$ and $-237(\mathrm{G} / \mathrm{A}))$ were 
investigated. For the TNF promoter polymorphism at position $-1031(\mathrm{~T} / \mathrm{C})$, we observed a significant increase in the frequency of the rarer TNF -1031C allele in the PTLD subject group compared with the non-PTLD transplant control group $(37 \%$ vs $19 \%$;
$P=0.005$; Figure $1 \mathrm{~A}$; Table 1$)$ and when compared with the healthy control group $(37 \%$ vs $23 \%$; $P=0.01$; Table 1). A significant difference was also found in the genotype frequency of this polymorphism with homozygous CC and heterozygous TC

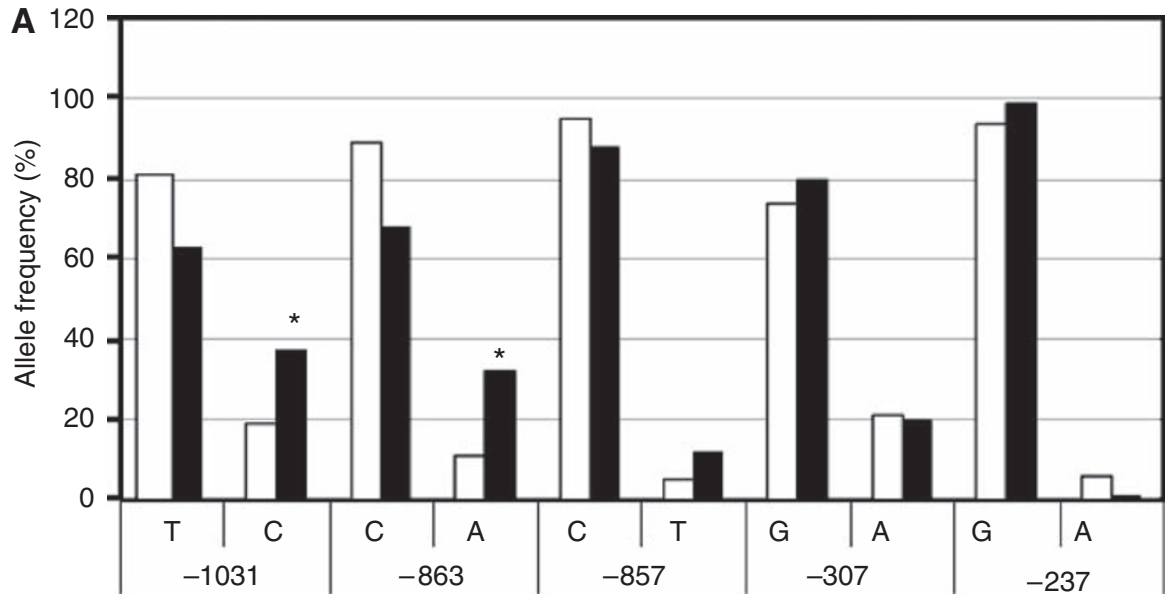

TNF promoter polymorphism

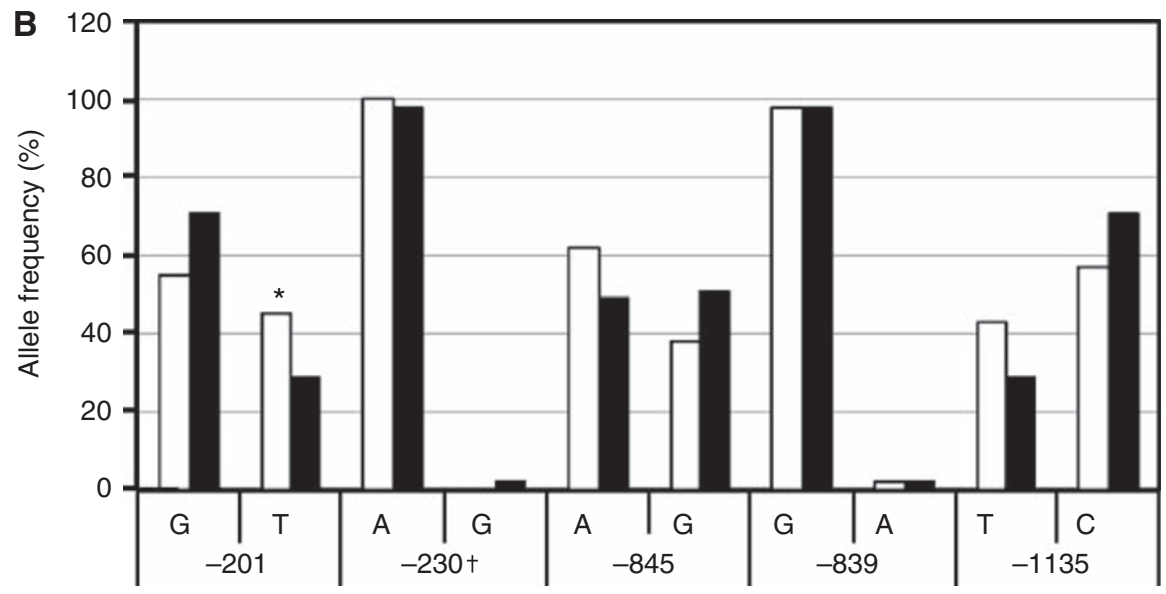

TNF receptor I

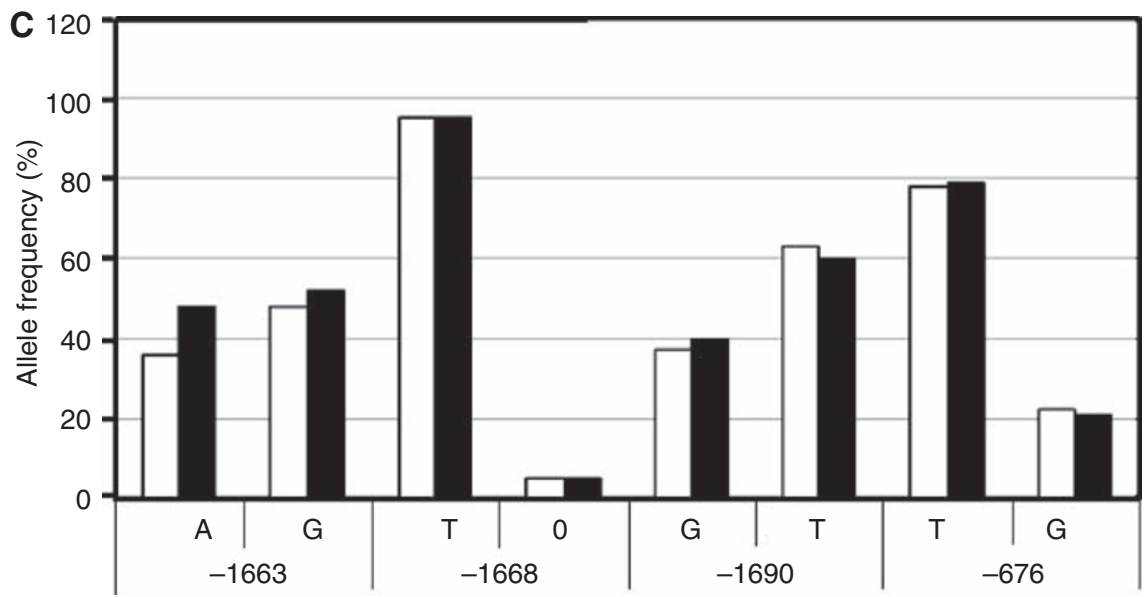

TNF receptor II

Figure I Allele frequencies of TNF promoter polymorphisms in transplant patients with and without PTLD. Allele frequencies (\%) were calculated for each polymorphic allele and statistical analysis performed using Fisher's exact two-sided tests (significant $P$-value, $P<0.05)$. Black bars $(\boldsymbol{\square})$ represent PTLD transplant patients and white bars $(\square)$ transplant control patients. Significant $P$-value highlighted with asterisk (*). (A) Polymorphic alleles from the TNF- $\alpha$ promoter; (B) polymorphic alleles from TNF receptor I; (C) polymorphic alleles from TNF receptor II. 
Table I Allele frequencies of the TNF-á promoter and TNF receptor polymorphisms in transplant patients with and without PTLD

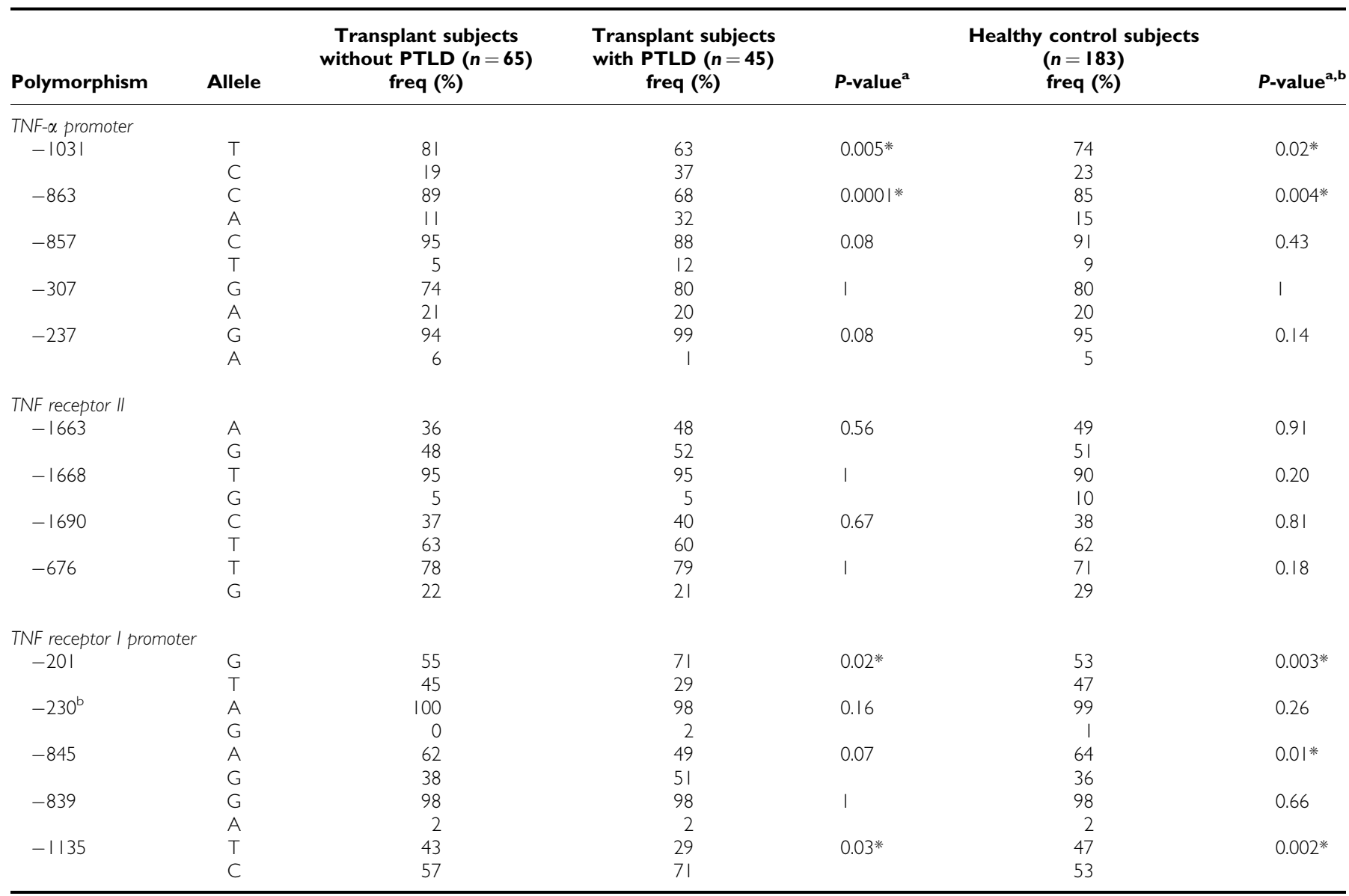

Abbreviations: freq = frequency; TNF = tumour necrosis factor. ${ }^{a}$ Fisher's exact two-sided $P$-value (not adjusted for multiple testing). ${ }^{b}$ Comparison between post-transplant lymphoproliferative disease (PTLD) and healthy control groups; *significant $P$-value, $P<0.05$.

frequencies increased whereas homozygous TT frequencies were decreased (CC: 9\% PTLD subjects vs 3\% transplant control subjects; TC: $38 \%$ vs $32 \%$; TT: $44 \%$ vs $65 \%, P=0.01$; CC: $3 \%$, TC: $40 \%$, TT: $57 \% ; P=0.001$ for healthy control subjects, Table 2).

Likewise for position TNF-863(C/A) we observed a significant increase in the TNF-863A allele frequency in the PTLD transplant group compared with the transplant control group (32\% vs $11 \%$; $P=0.0001$; Figure $1 \mathrm{~A}$; Table 1 ) and when compared with the healthy control group $(32 \%$ vs $15 \% ; P=0.0004$; Table 1$)$. Comparison of the genotype frequencies between each group also showed a significant difference for this polymorphism (CC: $44 \%$ PTLD subjects vs $82 \%$ transplant control subjects; CA: $47 \%$ vs $15 \%$; AA: $9 \%$ vs $3 \%$; $P=0.0003$. CC: $73 \%$, CA: $25 \%$, AA: $2 \%, P=0.0007$; Table 2). The remaining investigated TNF promoter polymorphisms, at nucleotide positions $-857(\mathrm{C} / \mathrm{T}),-307(\mathrm{G} / \mathrm{A})$ and $-237(\mathrm{G} / \mathrm{A})$, showed no differences in allele or genotype frequency between transplant patients with or without PTLD or healthy controls (Table 2).

From the investigated TNF promoter polymorphisms it is possible to assign one out of six TNF promoter haplotypes, detailed in Table 3 (Grutters et al, 2002). Haplotype-1 (TCCGG) was under represented within the PTLD transplant group compared with the transplant control group $(62 \%$ vs $83 \%$, $P=0.02 ; \quad \mathrm{OR}=2.6 \quad(95 \% \quad \mathrm{CI}: 1.2-7.29))$ whereas haplotype-3 (CACGG) was over represented $(50 \%$ vs $14 \%, P=0.0001$; $\mathrm{OR}=0.16$ (95\% CI: $0.06-0.4$; Table 3$)$. Haplotype-3 remained significantly over represented when compared with healthy controls ( $50 \%$ vs $26 \%, P=0.003$; Table 3 ). Haplotypes-2, $-4,-5$ and -6 were comparable between all groups (Table 3 ).
Decreased frequency of the TNFRI promoter $-201 \mathrm{~T}$ and increased frequency of $-1135 \mathrm{C}$ alleles in PTLD subjects

Several polymorphisms within the TNFRII locus (exon-10 nucleotide position $+1663(\mathrm{~A} / \mathrm{G}),+1668(\mathrm{~T} / \mathrm{G}),+1690(\mathrm{C} / \mathrm{T})$ and exon- 6 , position $+676(\mathrm{~T} / \mathrm{G})$ ) and TNFRI promoter regions (nucleotide positions $-201(\mathrm{G} / \mathrm{T}), \quad-230(\mathrm{~A} / \mathrm{G}), \quad-845(\mathrm{~A} / \mathrm{G}), \quad-839(\mathrm{G} / \mathrm{A})$, $-1135(\mathrm{~T} / \mathrm{C})$ ) were investigated. Analysis of the TNFRI promoter at position -201 showed a significant decrease in the frequency of the $-201 \mathrm{~T}$ allele within the PTLD group compared with the transplant control group $(45 \%$ vs $29 \%, P=0.02$; Figure $1 B$; Table 1). This was also true when the PTLD cohort was compared with the healthy control group ( $47 \%$ vs $29 \%, P=0.003$; Table 1). The TNFRI promoter $-1135 \mathrm{C}$ allele was significantly increased in the PTLD group compared with the transplant control group $(71 \%$ vs $57 \%, P=0.03$; Figure 1B; Table 1) and also when compared with the healthy control group ( $71 \%$ vs $53 \%, P=0.002$; Table 1$)$. The TNFR1 promoter $-845 \mathrm{G}$ allele was significantly increased in the PTLD transplant group when compared with the healthy control group but not when compared with the transplant control group ( $51 \%$ vs $36 \%, P=0.01$; Table 1 ). No differences were observed for TNFRII positions $-1663,-1668,-1690,-676$ or TNFRI promoter positions $-230,-845$ and -839 (Figure $1 \mathrm{~B}$ and C; Table 1).

Genotype frequencies of TNF receptors I and II polymorphisms were also compared between the PTLD and transplant control groups. Analysis of the TNFRI promoter at position -201 showed a significant increase in the frequency of the -201GG genotype and a decrease of the -201TT genotype in the PTLD group compared with the transplant and healthy control groups 
Table 2 Genotype frequencies of the TNF promoter, TNF receptor II and TNF receptor I promoter polymorphisms in transplant patients with and without PTLD

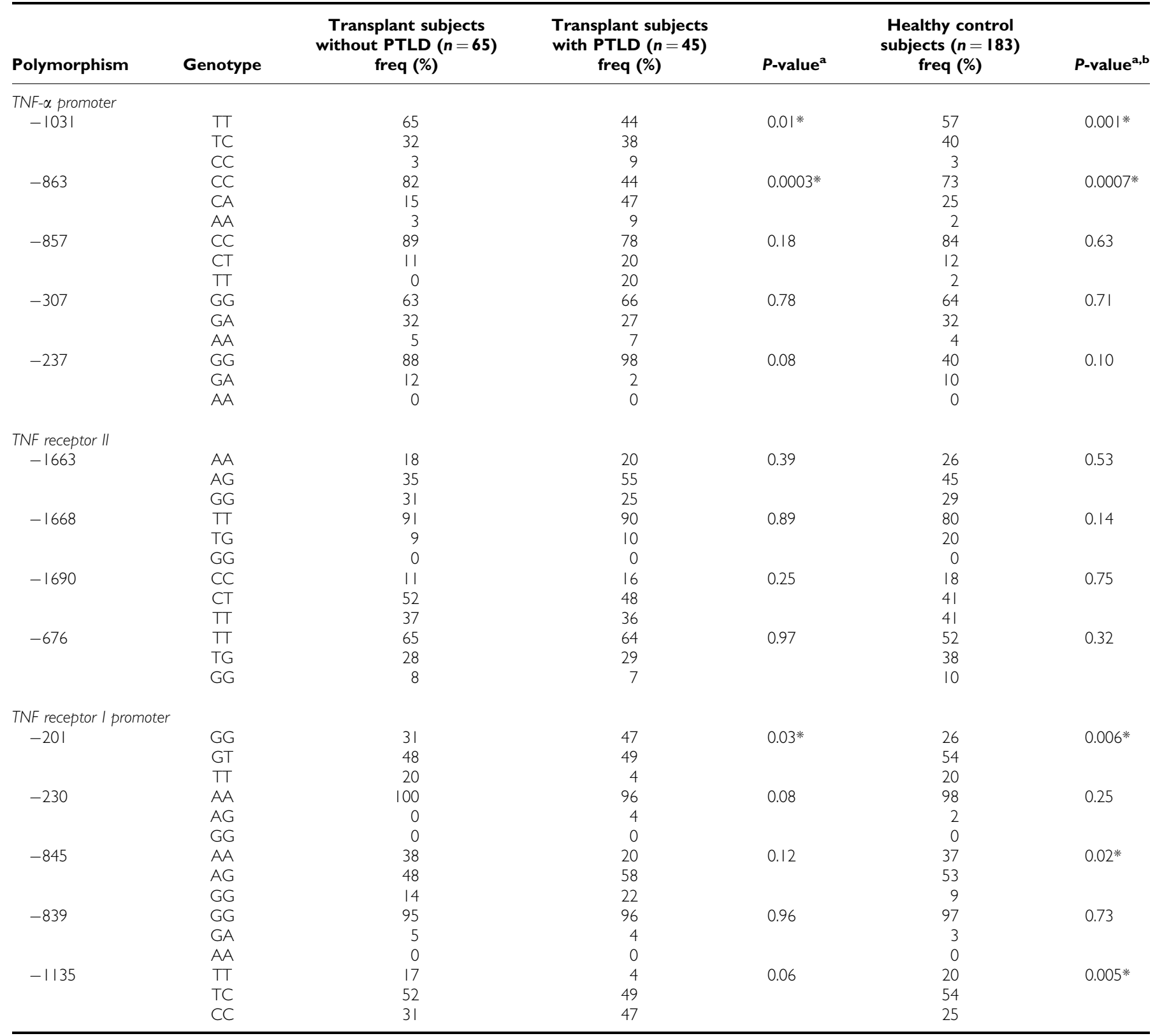

Abbreviations: freq = frequency; TNF = tumour necrosis factor. ${ }^{\mathrm{a} C}$ Chi-square $3 \times 2$ contingency table (not adjusted for multiple testing). ${ }^{\mathrm{b}}$ Comparison between post-transplant lymphoproliferative disease (PTLD) and healthy control groups; *significant $P$-value, $P<0.05$.

(GG: $47 \%$ vs $31 \%$, TT: $4 \%$ vs $20 \%, P=0.03$ for PTLD vs transplant controls; GG: $47 \%$ vs $26 \%$, TT: $4 \%$ vs $20 \%, P=0.006$ for PTLD vs healthy controls; Table 2). Similar analysis of the TNFRI promoter position -1135 resulted in an observed decrease in the frequency of the genotype $-1135 \mathrm{TT}(4 \%$ vs $17 \%)$ and an increase in the frequency of genotype -1135 CC (47\% vs 31\%) within the PTLD group compared with the transplant control group, however, this did not reach significance $(P=0.06$; Table 2$)$. Significance was reached when the PTLD transplant group was compared with healthy controls (TT: $4 \%$ vs 20\%, CC: $47 \%$ vs $25 \%, P=0.005$; Table 2). A significant decrease in the GG genotype of -845 was also noted between the PTLD transplant group and healthy controls (22\% vs $9 \%, P=0.02$; Table 2$)$. No genotypic differences were observed for TNFRII positions $-1663,-1668,-1690,-676$ or for TNFRI promoter positions $-230,-845$ and -839 (Table 2).
Determination of the TNFRI promoter haplotypes from nucleotide positions $-201,-230$ and -845 results in five possible haplotypes, detailed in Table 4. An increase in the frequency of haplotype-1 (GAG) was observed in the PTLD group compared with the transplant control group (80\% vs $63 \%)$ and a decrease in the frequency of haplotype-3 (TAA: $53 \%$ vs $69 \%$, Table 4). However, these differences did not reach statistical significance $(P=0.05$ and 0.11 , respectively). However, both haplotypes- 1 and -3 were significantly different when the PTLD cohort was compared with the healthy control cohort (GAG: $80 \%$ vs 63\%, $P=0.03$; TAA: $53 \%$ vs $74 \%, P=0.01$; Table 4 ).

No difference in frequency was observed for any of the polymorphic alleles, genotypes or haplotypes investigated from the LT- $\alpha$, IL-1, IL- 6 and IL-10 loci and for those alleles from the IL-1R1 and IL-10RI loci. 
Table 3 TNF promoter haplotypes in PTLD and control subjects

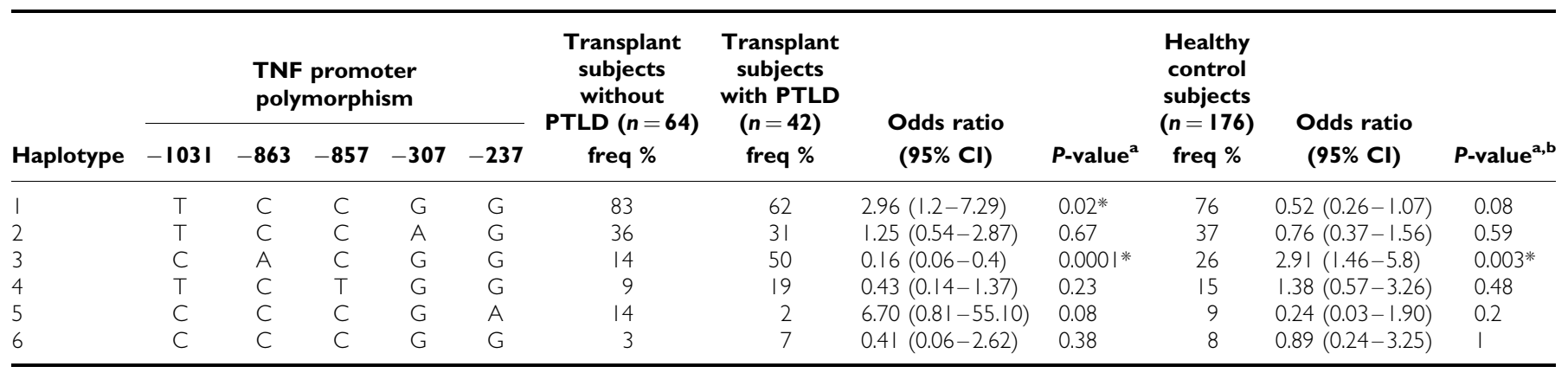

Abbreviations: $\mathrm{Cl}=$ confidence interval; freq $=$ frequency; $\mathrm{TNF}=$ tumour necrosis factor. Data are given as frequency with absolute numbers in parentheses. ${ }^{\mathrm{a} F i s h e r}$ 's exact twosided $P$-value (not adjusted for multiple testing). ${ }^{b}$ Comparison between post-transplant lymphoproliferative disease (PTLD) and healthy control groups; *significant $P$-value, $P<0.05$.

Table 4 TNF receptor I promoter haplotypes in PTLD

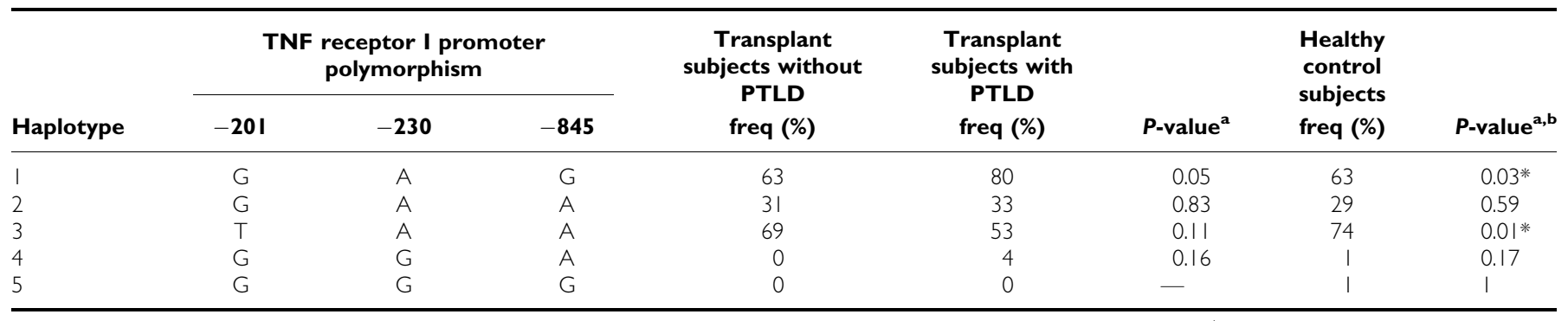

Abbreviations: freq = frequency; TNF = tumour necrosis factor. ${ }^{a}$ Fisher's exact two-sided $P$-value (not adjusted for multiple testing). ${ }^{b}$ Comparison between post-transplant lymphoproliferative disease (PTLD) and healthy control groups; *significant $P$-value, $P<0.05$.

\section{Increased plasma levels of TNF- $\alpha$ in patients with EBV-positive PTLD}

Polymorphisms within the TNF- $\alpha$ promoter regions have been associated with variation in the level of cytokine produced by cells (Koss et al, 2000). We therefore measured the levels of TNF- $\alpha$ in the plasma of our patient groups EBV-positive PTLD $(n=25)$ and non-PTLD transplant controls $(n=25)$ as well as in a cohort of healthy EBV sero-positve controls $(n=25)$. Similar plasma TNF- $\alpha$ levels were observed for the healthy EBV sero-positve and nonPTLD transplant control groups (range $0-8.147 \mathrm{pg} \mathrm{ml}^{-1}$, median 0; and $0-9.981 \mathrm{pg} \mathrm{ml}^{-1}$, median 0 , respectively). In contrast, there was a significant increase in the level of TNF- $\alpha$ in plasma obtained from PTLD patients (range $0-97.97 \mathrm{pg} \mathrm{ml}^{-1}$, median 3.801; $P=0.02$; Figure 2). We next assessed the TNF- $\alpha$ levels in relation to the polymorphic alleles and genotype of the PTLD patient group. For the TNF promoter polymorphism at position $-1031(\mathrm{~T} /$ $\mathrm{C})$, we assessed those with ( $\mathrm{C}$ positive) and without ( $\mathrm{C}$ negative) the risk allele. A median value of $4.053 \mathrm{pg} \mathrm{ml}^{-1}$ (range $0-66.69$ ) was observed for C-negative individuals compared with a median of $2.547 \mathrm{pg} \mathrm{ml}^{-1}$ (range 0-97.97) for C-positive individuals, however this was not a significant difference (Figure 3A). Similarly, we compared levels between the three genotypes and found no significant differences in TNF- $\alpha$ levels (Figure 3A). No significant difference in TNF- $\alpha$ levels for alleles and genotypes was observed for TNF promoter polymorphisms at position $-863(\mathrm{C} / \mathrm{A})$, TNF promoter haploytpes -1 and -3 , or TNF receptor loci $-201(\mathrm{G} / \mathrm{T})$ and $-1135(\mathrm{~T} / \mathrm{C})$ (Figures 3B, 3C; Table 5).

\section{DISCUSSION}

In this study, we have assessed polymorphisms within the TNF, LT- $\alpha$, IL-1- $\alpha$, IL- 6 and IL-10 loci and their corresponding receptor loci for evidence of an association with the development of

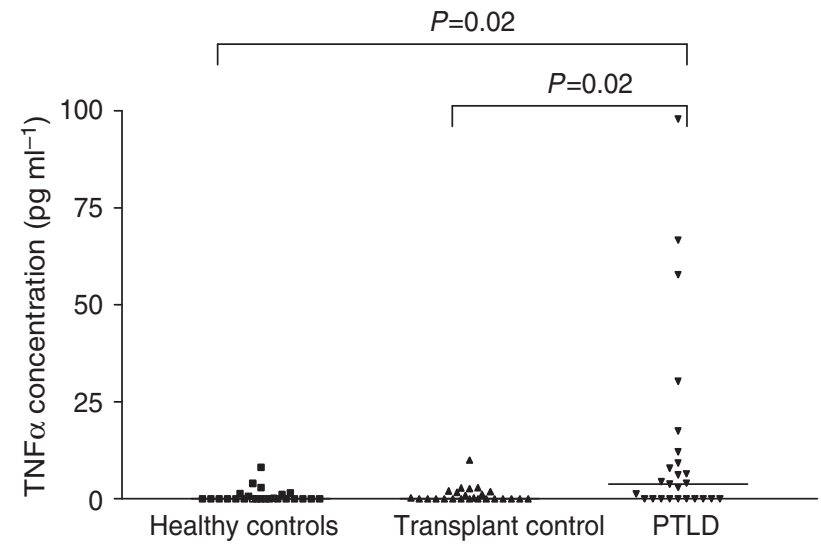

Figure 2 TNF- $\alpha$ levels in plasma from healthy controls and transplant patients with and without PTLD. The TNF- $\alpha$ level in plasma was measured by ELISA and the concentration estimated in relation to a set of known standards. Median levels are highlighted by the black bars and statistical analysis performed using the Mann-Whitney $U$ test (significant $P$-value, $P<0.05)$.

EBV-associated PTLD. The rarer alleles of the TNF promoter polymorphisms at nucleotide positions -1031(C allele) and -863(A allele) were found to be significantly increased in EBVpositive PTLD cases compared with non-PTLD transplant and healthy controls. Likewise, genotypes containing the non-ancestral allele were also significantly increased in the EBV-positive PTLD cases compared with transplant and healthy control groups. Furthermore, these polymorphic differences within the TNF promoter region resulted in a significant increase of TNF haplotype-3 (CACGG) and a decrease in TNF haplotype-1 

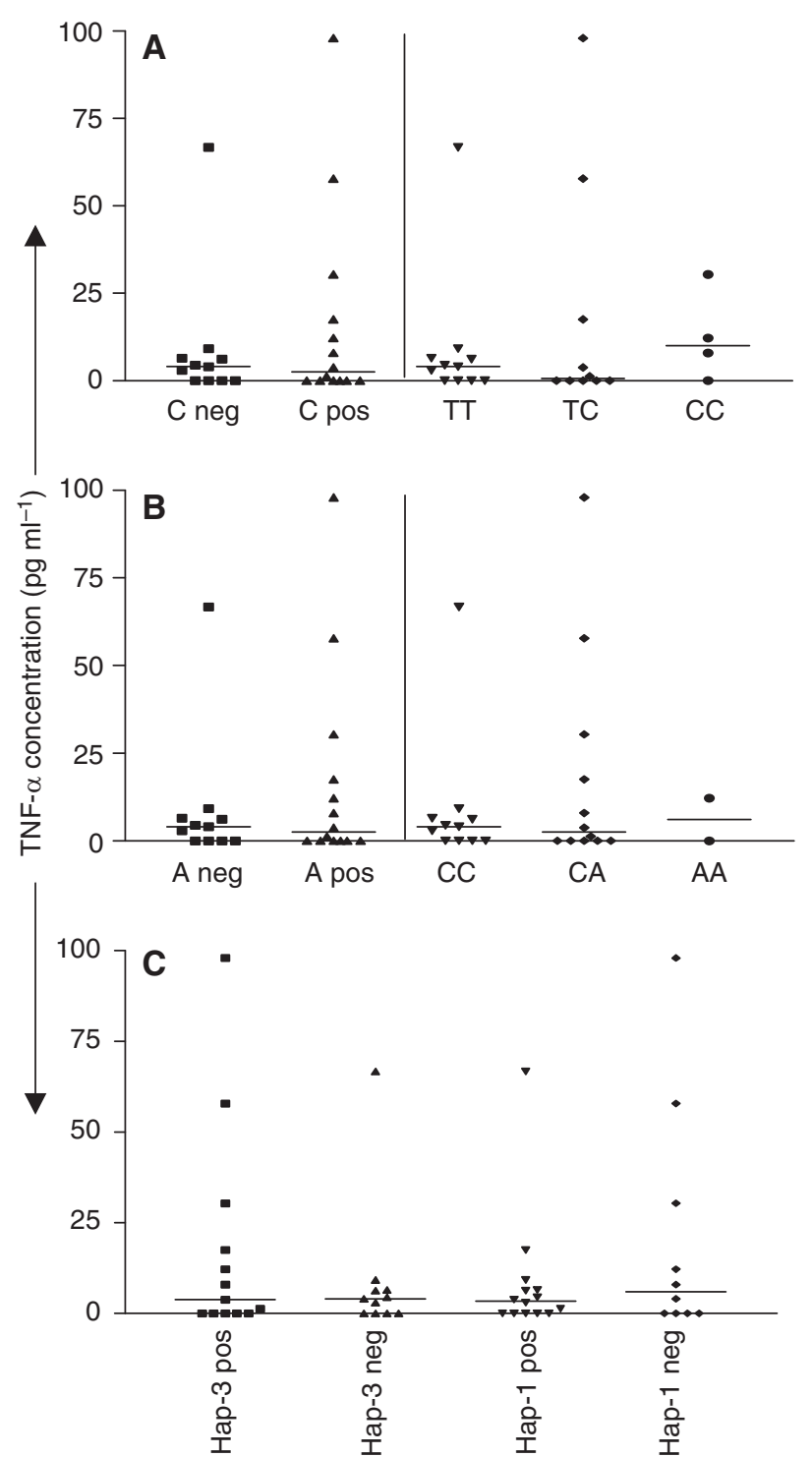

Figure 3 TNF- $\alpha$ levels in plasma from PTLD patients in relation to genetic variance. The level of TNF- $\alpha$ was estimated and assessed in relation to variant allele status (negative or positive), genotype or haplotype for position $-103 \mid(T / C)(\mathbf{A}),-863(\mathrm{C} / \mathrm{A})(\mathbf{B})$ and for the TNF- $\alpha$ promoter haplotype $(\mathbf{C})$. Median levels are highlighted by the black bars and statistical analysis performed using the Mann-Whitney $U$ test or one-way ANOVA test (significant $P$-value, $P<0.05$ ).

(TCCGG) in EBV-positive PTLD subjects compared with transplant and healthy controls suggesting an important role for these haplotypes in determining susceptibility to EBV-positive lymphoma after transplantation. Interestingly, the frequency of the TNFRI promoter $-1135 \mathrm{C}$ allele was also significantly increased and the -201T allele decreased in EBV-positive PTLD compared with transplant and healthy controls. A corresponding increase in the frequency of the homozygous $-1135 \mathrm{CC}$ and a decrease in the -201TT genotypes were also observed for the EBV-positive PTLD group confirming the importance of the TNF family of cytokines and their receptors in the development of EBV-positive PTLD.

TNF is a member of the TNF family whose members function as potent mediators of immune regulation and inflammation. The TNF genes are located in the HLA class III region on chromosome 6 p21.3 and are closely linked to the polymorphic HLA-B and -DR regions (Nedwin et al, 1985). TNF cytokines bind to two cellular
Table 5 TNF- $\alpha$ levels in plasma of PTLD patients; genetic subgroup analysis

\begin{tabular}{|c|c|c|c|}
\hline \multicolumn{4}{|c|}{ Levels of TNF- $\alpha$ in Plasma } \\
\hline Polymorphic loci & Number & $\begin{array}{c}\text { Median } \\
\left(\text { range, } \mathrm{pg} \mathrm{ml}^{-1}\right)\end{array}$ & $P$-value ${ }^{a}$ \\
\hline \multicolumn{4}{|l|}{ TNF 1031} \\
\hline$C$ allele negative & || & $4.053(0-66.69)$ & \multirow[b]{2}{*}{0.85} \\
\hline C allele positive & 14 & $2.547(0-97.97)$ & \\
\hline$T \top$ & 11 & $4.053(0-66.69)$ & \multirow{3}{*}{0.56} \\
\hline $\mathrm{TC}$ & 10 & $0.645(0-97.97)$ & \\
\hline CC & 4 & $10.06(0-30.34)$ & \\
\hline \multicolumn{4}{|l|}{ TNF 865} \\
\hline A allele negative & || & $4.053(0-66.69)$ & \multirow{3}{*}{0.85} \\
\hline A allele positive & 14 & $2.547(0-97.97)$ & \\
\hline $\mathrm{CC}$ & $\mid 1$ & $4.053(0-66.69)$ & \\
\hline CA & 12 & $2.547(0-97.97)$ & \multirow[t]{2}{*}{0.96} \\
\hline AA & 2 & $6.088(0-12.18$ & \\
\hline \multicolumn{4}{|l|}{ TNF haplotype } \\
\hline Haplotype-3 positive & 13 & $3.801(0-97.97)$ & \multirow{2}{*}{0.68} \\
\hline Haplotype- 3 negative & $\mid 1$ & $4.053(0-66.69)$ & \\
\hline Haplotype-I positive & 14 & $3.378(0-66.69)$ & \multirow{2}{*}{0.53} \\
\hline Haplotype-I negative & 10 & $5.997(0-97.97)$ & \\
\hline \multicolumn{4}{|l|}{ TNFR 201} \\
\hline $\mathrm{T}$ allele negative & 13 & $4.427(0-97.97)$ & \multirow{3}{*}{0.31} \\
\hline $\mathrm{T}$ allele positive & 12 & $1.477(0-30.34)$ & \\
\hline GG & 13 & $4.427(0-97.97)$ & \\
\hline GT & 10 & $0(0-17.52)$ & \multirow[t]{2}{*}{0.27} \\
\hline $\mathrm{TT}$ & 2 & $16.64(0-13.69)$ & \\
\hline \multicolumn{4}{|l|}{ TNFR / / 35} \\
\hline C allele negative & 2 & I $6.64(0-30.34)$ & \multirow[t]{3}{*}{ - } \\
\hline $\mathrm{C}$ allele positive & 23 & $3.801(0-97.97)$ & \\
\hline TT & 2 & $16.64(0-30.34)$ & \\
\hline $\mathrm{TC}$ & 10 & $0(0-17.52)$ & \multirow[t]{2}{*}{0.27} \\
\hline $\mathrm{CC}$ & 13 & $4.427(0-97.97)$ & \\
\hline
\end{tabular}

aMann-Whitney $\cup$ Test or one-way ANOVA (Significant $P$-value, $P<0.05$ ).

receptors; TNFRI, which is widespread in many cells types and activated by soluble ligand, and the TNFRII that is primarily expressed on haemopoietic cells (Chan et al, 2000; Locksley et al, 2001). Both receptors are also shed and act as competitive soluble TNF-binding proteins consequently affecting the levels of TNF. In the case of TNF, ligand-receptor binding leads to the recruitment of intracellular adaptor proteins that activate several signal transduction pathways including the transcription factor NF- $\kappa \mathrm{B}$ and the apoptotic pathway through capsase 8 (Balkwill, 2006). Many pathological situations are determined by the balance between such survival and apoptotic signals. Therefore, gene polymorphisms that alter this signalling process either through the ligand or through the receptor are important.

The function of the TNF-863A variant highlighted in our PTLD cohort has been widely investigated. The nucleotide change from C to A has been shown to have a clear effect on the binding of the NF- $\kappa$ B transcription complex to its DNA-binding domain. In particular, the affinity of the $\mathrm{NF} \kappa \mathrm{B} \mathrm{p} 50-\mathrm{p} 50$ heterodimer, which acts as a transcriptional repressor when bound to the TNF promoter, is significantly decreased for the $-863 \mathrm{~A}$ variants (Udalova et al, 2000). Decreased binding is thought to result in inadequate downregulation of TNF gene expression and therefore increased TNF production. As yet, there is no comparable molecular data for the TNF-1031C allele (however there is some degree of linkage between the -1031 and -863 alleles) or for the TNFRI promoter $-201 \mathrm{~T}$ and $-1135 \mathrm{C}$ alleles. 
Analysis of TNF- $\alpha$ levels in plasma from our cohorts showed a significant difference in levels between transplant controls and EBV-positive PTLD patients in general with higher TNF- $\alpha$ levels detected in the EBV-positive PTLD group. We did not detect a significant difference in TNF- $\alpha$ levels when we assessed the effect of the genetic variants within the PTLD cohort however there was a slight trend for higher TNF- $\alpha$ levels in the variant groups (Figure 3 ). This trend may become stronger with a larger cohort of PTLD individuals carrying the variant allele. Determining TNF- $\alpha$ levels in variant positive and negative individuals after transplant and before development of disease would provide further information on the predictive value of TNF- $\alpha$ levels.

Interestingly, the presence of the TNF-863A allele has also been positively associated with susceptibility to B-cell malignancies (non-Hodgkin's lymphomas) in the general population (Spink et al, 2006). Possession of specific alleles that act to increase TNF expression may therefore be central to the pathogenesis and susceptibility to lymphoid disease. Indeed, TNF-based mechanisms, such as direct DNA damage, anti-apoptotic activity and induction of cytokines, have been implicated in several cancers (Balkwill, 2006).

In summary, we have shown an association between variant alleles of the TNF promoter and the subsequent TNF promoter haplotype with the development of EBV-positive PTLD (although it has to be noted that this data set was not adjusted for multiple testing and so type 1 error cannot be completely ruled out). We have also shown that TNF- $\alpha$ levels are significantly higher in EBV-positive PTLD patients. However, there remains a group of
EBV-positive PTLD patients who do not carry these alleles, genotypes or haplotypes, perhaps indicating that these polymorphisms are not independently functional and that other, as yet, unidentified variants are in linkage disequlibrium with these loci. These data require confirmation in a second, larger sized cohort to be certain of an association (power calculations based on this pilot study indicate a PTLD and non-PTLD transplant group size of 105 subjects would provide $80 \%$ power, $95 \% \mathrm{CI}, \mathrm{OR}=2.5$ ) and further analysis of soluble TNF levels may offer some information on the functional activity of these polymorphic alleles. Nevertheless, the genotypic evidence for the involvement of TNF in EBV-positive PTLD presented here provides further information for identifying those most at risk.

\section{ACKNOWLEDGEMENTS}

Statistical advice was obtained from Dr Craig Higgins (Department of Epidemiology and Population Health, London School of Hygiene and Tropical Medicine, London) and Colette Smith (Research Department of Infection and Population Health, UCL Medical School, London). Thanks also to Dr Anna Lagan, National Heart and Lung Institute, Imperial College, London, for help with cytokine SSP-PCR. This work was supported by grants from CRUK (C307/A3869) and MRC (UK) (G 9826804).

Supplementary Information accompanies the paper on British Journal of Cancer website (http://www.nature.com/bjc)

\section{REFERENCES}

Babel N, Vergopoulos A, Trappe R, Oertel S, Hammer MM, Karaianov S, Schneider N, Riess H, Papp-Vary M, Neuhaus R, Gondek L, Volk H, Reinke P (2007) Evidence for genetic susceptibility towards development of posttransplant lymphoproliferative disorder in solid organ recipients. Transplantation 84: $387-391$

Balkwill $\mathrm{F}$ (2006) TNF-alpha in promotion and progression of cancer. Cancer Metastasis Rev 25: 409-416

Benden C, Aurora P, Burch M, Cubitt D, Lloyd C, Whitmore P, Neligan SL, Elliott MJ (2005) Monitoring of Epstein-Barr viral load in pediatric heart and lung transplant recipients by real-time polymerase chain reaction. $J$ Heart Lung Transplant 24: 2103-2108

Bogunia-Kubik K, Mlynarczewska A, Jaskula E, Lange A (2006) The presence of IFNG $3 / 3$ genotype in the recipient associates with increased risk for Epstein-Barr virus reactivation after allogeneic haematopoietic stem cell transplantation. Br J Haematol 132: 326-332

Brennan FM, McInnes IB (2008) Evidence that cytokines play a role in rheumatoid arthritis. J Clin Invest 118: 3537-3545

Chan FK-M, Siegel RM, Lenardo MJ (2000) Signaling by the TNF receptor superfamily and $\mathrm{T}$ cell homeostasis. Immunity 13: 419-422

Choquet S, Leblond V, Herbrecht R, Socie G, Stoppa AM, Vandenberghe P, Fischer A, Morschhauser F, Salles G, Feremans W, Vilmer E, Peraldi MN, Lang P, Lebranchu Y, Oksenhendler E, Garnier JL, Lamy T, Jaccard A, Ferrant A, Offner F, Hermine O, Moreau A, Fafi-Kremer S, Morand P, Chatenoud L, Berriot-Varoqueaux N, Bergougnoux L, Milpied N (2006) Efficacy and safety of rituximab in B-cell post-transplantation lymphoproliferative disorders: results of a prospective multicenter phase 2 study. Blood 107: 3053-3057

Choquet S, Oertel S, Leblond V, Riess H, Varoqueaux N, D+Ârken B, Trappe R (2007) Rituximab in the management of post-transplantation lymphoproliferative disorder after solid organ transplantation: proceed with caution. Ann Hematol 86: 599-607

Crawford DH, Macsween KF, Higgins CD, Thomas R, McAulay K, Williams H, Harrison N, Reid S, Conacher M, Douglas J, Swerdlow AJ (2006) A cohort study among university students: identification of risk factors for Epstein-Barr virus seroconversion and infectious mononucleosis. Clin Infect Dis 43: 276-282
Crawford DH, Swerdlow AJ, Higgins CD, McAulay K, Harrison N, Williams H, Britton K, Macsween KF (2002) Sexual history and Epstein-Barr virus infection. J Infect Dis 186: $731-736$

Davis JE, Sherritt MA, Bharadwaj M, Morrison LE, Elliott SL, Kear LM, Maddicks-Law J, Kotsimbos T, Gill D, Malouf M, Falk MC, Khanna R, Moss DJ (2004) Determining virological, serological and immunological parameters of EBV infection in the development of PTLD. Int Immunol 16: $983-989$

Feldmann M (2008) Many cytokines are very useful therapeutic targets in disease. J Clin Invest 118: 3533 - 3536

Grutters JC, Sato H, Pantelidis P, Lagan AL, McGrath DS, Lammers JW, van den Bosch JMM, Wells AU, du Bois RM, Welsh KI (2002) Increased frequency of the uncommon tumor necrosis factor -857T allele in British and Dutch patients with sarcoidosis. Am J Respir Crit Care Med 165: $1119-1124$

Haque T, Wilkie GM, Jones MM, Higgins CD, Urquhart G, Wingate $\mathrm{P}$, Burns D, McAulay K, Turner M, Bellamy C, Amlot PL, Kelly D, MacGilchrist A, Gandhi MK, Swerdlow AJ, Crawford DH (2007) Allogeneic cytotoxic T-cell therapy for EBV-positive posttransplantation lymphoproliferative disease: results of a phase 2 multicenter clinical trial. Blood 110: 1123-1131

Helminen M, Lahdenpohja N, Hurme M (1999) Polymorphism of the interleukin-10 gene is associated with susceptibility to Epstein-Barr virus infection. J Infect Dis 180: 496-499

Hopwood PA, Brooks L, Parratt R, Hunt BJ, Maria B, Alero TJ, Magdi Y, Crawford DH (2002) Persistent Epstein-Barr virus infection: unrestricted latent and lytic viral gene expression in healthy immunosuppressed transplant recipients1. Transplantation 74: $194-202$

Hurme M, Helminen M (1998) Polymorphism of the IL-1 gene complex in Epstein-Barr virus seronegative and seropositive adult blood donors. Scand J Immunol 48: 219-222

Koss K, Satsangi J, Fanning GC, Welsh KI, Jewell DP (2000) Cytokine (TNFa, LTa and IL-10) polymorphisms in inflammatory bowel diseases and normal controls: differential effects on production and allele frequencies. Genes Immun 1: 185-190 
Lee TC, Savoldo B, Barshes NR, Rooney CM, Heslop HE, Gee AP, Caldwell Y, Scott JD, Goss JA (2006) Use of cytokine polymorphisms and Epstein-Barr virus viral load to predict development of post-transplant lymphoproliferative disorder in paediatric liver transplant recipients. Clin Transplant 20: 389-393

Locksley RM, Killeen N, Lenardo MJ (2001) The TNF and TNF receptor superfamilies: integrating mammalian biology. Cell 104: $487-501$

Nalesnik MA (2002) Clinicopathologic characteristics of post transplant lymphoproliferative disorders. Recent Results Cancer Res 159: 9-18

Nedwin GE, Naylor SL, Sakaguchi AY, Smith D, Jarrett-Nedwin J, Pennica D, Goeddel DV, Gray PW (1985) Human lymphotoxin and tumor necrosis factor genes: structure, homology and chromosomal localization. Nucleic Acids Res 13: 6361-6373

Ollier WER (2004) Cytokine genes and disease susceptibility. Cytokine 28: $174-178$

Opelz G, Dohler B (2004) Lymphomas after solid organ transplantation: a collaborative transplant study report. Am J Transplant 4: 222-230

Paya C, Fung J, Nalesnik M, Kieff E, Green M, Gores G, Habermann T, Wiesner R, Swinnen L, Woodle E, Bromberg J (1999) Epstein-Barr virusinduced posttransplant lymphoproliferative disorders. Transplantation 68: $1517-1525$

Pratesi C, Bortolin M, Bidoli E, Tedeschi R, Vaccher E, Dolcetti R, Guidoboni M, Franchin G, Barzan L, Zanussi S, Caruso C, De Paoli P (2006) Interleukin-10 and interleukin-18 promoter polymorphisms in an Italian cohort of patients with undifferentiated carcinoma of nasopharyngeal type. Cancer Immunol Immunother 55: $23-30$

Riddler SA, Breinig MC, McKnight JL (1994) Increased levels of circulating Epstein-Barr virus (EBV)-infected lymphocytes and decreased EBV nuclear antigen antibody responses are associated with the development of posttransplant lymphoproliferative disease in solid-organ transplant recipients. Blood 84: $972-984$
Sato T, Fujieda M, Tanaka E, Miyamura $M$, Chikamoto $H$, Hisano $M$, Akioka Y, Ishiura Y, Dohno S, Maeda A, Hattori M, Wakiguchi H (2008) Monitoring of Epstein-Barr virus load and antibody in pediatric renal transplant patients. Paediatr Int 50: $454-458$

Savoldo B, Goss JA, Hammer MM, Zhang L, Lopez T, Gee AP, Lin YF, Quiros-Tejeira RE, Reinke P, Schubert S, Gottschalk S, Finegold MJ, Brenner MK, Rooney CM, Heslop HE (2006) Treatment of solid organ transplant recipients with autologous Epstein Barr virus-specific cytotoxic T lymphocytes (CTLs). Blood 108: 2942-2949

Spink CF, Keen LJ, Mensah FK, Law GR, Bidwell JL, Morgan GJ (2006) Association between non-Hodgkin lymphoma and haplotypes in the TNF region. Br J Haematol 133: 293-300

Swinnen LJ, Mullen GM, Carr TJ, Costanzo MR, Fisher RI (1995) Aggressive treatment for postcardiac transplant lymphoproliferation. Blood 86: $3333-3340$

Thomas R, McAulay K, Higgins C, Wilkie G, Crawford D (2005) Interferon gamma polymorphisms in posttransplant proliferative disease. Blood 106: $1502-1503$

Udalova IA, Richardson A, Denys A, Smith C, Ackerman H, Foxwell B, Kwiatkowski D (2000) Functional consequences of a polymorphism affecting NF-kappa B p50-p50 binding to the TNF promoter region. $\mathrm{Mol}$ Cell Biol 20: $9113-9119$

VanBuskirk A, Malik V, Xia D, Pelletier R (2001) A gene polymorphism associated with posttransplant lymphoproliferative disorder. Transplant Proc 33: 1834

Wheless SA, Gulley ML, Raab-Traub N, McNeillie P, Neuringer IP, Ford HJ, Aris RM (2008) Post-transplantation lymphoproliferative disease: Epstein-Barr virus DNA levels, HLA-A3, and survival. Am J Respir Crit Care Med 178: $1060-1065$

Wu MS, Huang SP, Chang YT, Shun CT, Chang MC, Lin MT, Wang HS, Lin JT (2002) Tumour necrosis factor-á and interleukin-10 promoter polymorphisms in Epstein-Barr virus associated gastric carcinoma. J Infect Dis 185: 106-109 